\title{
Vivências de estágio de ciências da natureza no contexto da educação do campo: uma análise crítico-reflexiva
}

\author{
Josimar de Jesus Santos*, Klayton Santana Porto**
}

\section{Resumo}

O objetivo deste artigo foi relatar as experiências vivenciadas no desenvolvimento do estágio supervisionado, como forma de discutir a relevância do estágio na formação inicial do professor e da professora de ciências da Educação do Campo. Para isso, buscamos relacionar as referências bibliográficas de autores importantes para a discussão da educação do campo, a saber: Arroyo (2004), Caldart (2004/2009), Fernandes (2004), Molina (2004), entre outros, com as experiências e vivências do autor no seu campo de estágio. O Estágio Supervisionado I na área de Ciências da Natureza foi realizado no Assentamento Alto Bonito, povoado de Cansanção Bahia, na Escola Municipal do Assentamento Alto Bonito, com a turma do nono ano da referida instituição educacional. As pesquisas bibliográfica, documental e de campo, com abordagem qualitativa, embasaram a escrita deste artigo, as quais foram analisadas a partir do cruzamento dos dados coletados por meio da observação, diálogos, entrevistas e atividades durante o estágio. Entre os resultados mais importantes, podemos destacar a gama de novos conhecimentos e experiências obtidos pelo estagiário e pelos alunos da escola do campo, além disso foram observadas a precariedade e a falta de investimentos tecnológicos e financeiros nas instituições escolares do campo, o que dificulta a efetivação de uma educação integral e de qualidade.

Palavras-chave: Educação do Campo. Ensino de Ciências. Estágio Supervisionado. Formação de Professores.

\footnotetext{
* Licenciado em Educação do Campo com habilitação em Ciências da Natureza pelo Centro de Ciência e Tecnologia em Energia e Sustentabilidade da Universidade Federal do Recôncavo da Bahia, campus de Feira de Santana-BA, Brasil. E-mail: josimar@gmail.com

* Doutor e mestre em Ensino, Filosofia e História das Ciências pela Universidade Federal da Bahia. Professor do Curso de Licenciatura em Educação do Campo com habilitações em Ciências da Natureza e Matemática e do Curso de Pós-graduação lato sensu em Ambiente e Sustentabilidade do Centro de Ciência e Tecnologia em Energia e Sustentabilidade da Universidade Federal do Recôncavo da Bahia, campus de Feira de Santana-BA, Brasil. Líder do Grupo de Estudos e Pesquisa em Ensino de Ciências e Formação de Professores. E-mail: klaytonuesb@hotmail.com
} 


\section{Introdução}

De acordo com Caldart (2009, p. 44)

[...] discutir sobre a Educação do campo hoje, buscando ser fiel aos seus objetivos de origem, exige um olhar de totalidade, em perspectiva, com uma preocupação metodológica, sobre como interpretá-la, combinada a uma preocupação política, de balanço do percurso e de compreensão das tendências de futuro para poder atuar sobre elas.

Essa preocupação política envolve os direitos da mulher, do homem, da criança, do jovem e do idoso do campo. Para Arroyo, Caldart e Molina (2004) é de suma importância que "a educação abarque o desenvolvimento, levando em consideração os aspectos da diversidade, da situação histórica particular de cada assentamento/ comunidade, seus recursos disponíveis, seus povos, suas expectativas, seus anseios". Para os autores, o currículo das escolas do campo deve ser fundamentado numa lógica de desenvolvimento humano integral, favorecendo a constituição da cidadania e da inclusão social, recolocando os sujeitos do campo no bojo do processo produtivo com justiça, bem-estar social e econômico.

A educação do campo exige, além do currículo contextualizado com a realidade territorial de forma integral, uma formação inicial e continuada dos profissionais da educação do campo. Segundo Baraúna (2009, p. 294) a

[...] formação do professor deve ter uma trajetória construída a partir de interesses do contexto sociopolítico das exigências colocadas pela realidade social, das finalidades da educação, do lugar que a educação ocupa nas políticas governamentais e das lutas travadas pela categoria e sociedade civil.

Baraúna (2009) afirma que a escola e os alunos do campo exigem do professor um projeto educacional diferenciado, de modo que este professor possa atuar concretamente nessa realidade, não apenas dando boas aulas, mas elaborando projetos que contribuam para fomentar o desenvolvimento desta realidade rural. Entretanto, trazer a temática sobre a educação do campo para os debates públicos é um desafio árduo que vem sendo proposto pelos Movimentos Sociais Campesinos e por diversos autores afins da área.

Dessa forma, a formação do professor das escolas do campo deve ser voltada para o contexto de vida dos educandos e de sua realidade social, política, econômica e cultural. A ênfase dessa nova prática pedagógica deve ser a busca de um projeto educacional que rompa com os moldes tradicionais de uma educação que não valo- 
riza o trabalho familiar no campo, em regime de economia sustentável e solidária. E neste prisma, o estágio tem um papel crucial na formação destes professores do campo, uma vez que o estágio na educação do campo deve buscar compreender a questão da educação do campo como direito a uma educação de qualidade, cujos sujeitos envolvidos têm que ter preservados a sua história e direitos, de modo que estes sejam partícipes de sua formação, enquanto sujeitos sociais, culturais, éticos e políticos (ARAÚJO; PORTO, 2019).

Estagiar não é apenas a etapa obrigatória de uma determinada disciplina no processo de aprendizagem do acadêmico (CARVALHO; FELICIANO; LUCAS, 2018). O estágio é, com certeza, um período extraordinário, no qual o envolvido desenvolve e adquire novas habilidades e conhecimentos prático-reais dos conteúdos/teorias aprendidos no âmbito acadêmico. É o espaço crucial para a interação e a comunicação entre o estagiário, os supervisores, os profissionais de uma dada instituição pública ou privada com uma instituição de ensino superior (pública ou privada); além desses benefícios, podemos visualizar ainda a troca de experiências, saberes, ferramentas e metodologias de atuação profissional usadas no cotidiano dos supervisores, ou seja, é a teoria se encontrando com a prática, e ambas, portanto, trazem uma gama riquíssima de contribuições para esta nova etapa vivida pelo estagiário.

Na visão de Pimenta e Lima (2004), a finalidade do estágio é propiciar ao aluno uma aproximação à realidade na qual atuará. As autoras afirmam que o estágio "é um momento de atitude investigativa, que envolve a reflexão e a intervenção na vida da escola, dos professores, dos alunos e da sociedade" (PIMENTA; LIMA, 2004, p. 34). Sob esta égide, o estágio curricular é compreendido como um método de conhecimento objetivo e prático e que proporciona subsídios para compreender vastos ensinamentos que conduzem ao exercício da sua profissão crucial para a construção dos conhecimentos que se respalda em aproximar o estagiário à sociedade (ARAÚJO; PORTO, 2019), cuja “dissociação entre teoria e prática resulta em um empobrecimento das práticas nas escolas, o que evidencia a necessidade de explicitar por que o estágio é teoria e prática (e não teoria ou prática)" (PIMENTA; LIMA, 2004, p. 41).

Neste artigo, buscamos estabelecer uma relação entre os conhecimentos advindos das vivências do Estágio de Ciências da Natureza em uma escola do campo com as bibliografias de autores que buscam fundamentar e embasar a educação do campo. As experiências vividas no estágio foram capazes de propiciar aos alunos da 
instituição escolar uma visão crítica e reflexiva acerca da sua história, da história da sua comunidade, do seu assentamento, do seu povo e da sua forma milenar de sobreviver e de cultivar a terra. Essa experiência vivida com os alunos teve como objetivo realizar diálogos e experiências que discorriam/tratavam sobre a questão agrária e a educação no campo, na sua localidade e na região circunvizinha, criando uma linha do tempo que mostrava o antes e o depois daquela comunidade.

As atividades propostas e executadas durante o estágio buscaram priorizar a história e a trajetória da educação do campo no Brasil, na região e na comunidade, sempre trazendo a realidade local do aluno para ser confrontada com a realidade mais ampla (nacional). Esses conhecimentos eram associados e trabalhados conjuntamente com conhecimentos das áreas de Matemática e das Ciências da Natureza. As principais temáticas estudadas envolviam questões do contexto de uma escola do campo, saberes sobre si mesmo e sobre a comunidade; sobre o surgimento dos seres humanos e como se deu sua evolução e sustento ao longo dos tempos; quanto aos aspectos físicos e naturais do Universo e do Planeta Terra, bem como suas modificações e a contribuição do ser humano para adensar tais mudanças sofridas; estudamos os aspectos e as formas de vida existentes na Terra; como é estruturado o Sistema Solar e o planeta Terra; como se deu o nascimento do universo, seus movimentos e as forças que agem na conservação e na mudança dos diversos sistemas existentes nele.

Desse modo, o objetivo deste artigo foi relatar as experiências vivenciadas no desenvolvimento do estágio supervisionado, como forma de discutir a importância do estágio na formação inicial do professor de ciências da Educação do Campo.

\section{O papel do estágio supervisionado na formação de professores de ciências da educação do campo}

\section{Educação do Campo}

A educação é um direito social destinado ao povo brasileiro de forma indisponível, inalienável e subjetivo. Segundo a Constituição Federal de 1988, no artigo 205, a educação é um direito de todos e dever do Estado e da família e será promovida e incentivada com a colaboração da sociedade, visando ao pleno desenvolvimento da pessoa, seu preparo para o exercício da cidadania e sua qualificação para o trabalho (BRASIL, 1988). 
O direito social à educação constitui um dos direitos que são garantidos pelo Estado brasileiro, no entanto, em meio a sua efetivação, ele não se dá de forma eficiente e igualitária, visto que as normas constitucionais e infraconstitucionais apontam que o currículo educacional, tradicional, deve ser complementado com um currículo contextualizado em acordo com a realidade de cada região e do povo que nela habita. Esse currículo contextualizado abrange de forma direta os conhecimentos e as realidades dos povos do campo, os quais têm meios de sobrevivência e aspectos culturais próprios, cujas realidades são próprias e diversificadas.

A educação do campo foi tratada com descaso e descontextualizarão durante muito tempo, mas, nas últimas décadas, como resultado das lutas do povo e dos movimentos sociais do campo, ela tem obtido grandes conquistas. Para Arroyo, Caldart e Molina (2004, p. 57)

[...] a escola, no meio rural, foi tratada como resíduo do sistema educacional brasileiro e, consequentemente, à população do campo foi negado o acesso aos avanços ocorridos nas duas últimas décadas como o reconhecimento e a garantia do direito à educação básica.

Na visão das autoras a educação do campo ficou relegada a segundo plano, ou pior, era apenas um resquício daquilo que deveria ter sido. Ou seja, havia um direito, mas este direito não era exercido de forma digna, justa e igualitária.

Leite (1999) salienta:

A educação rural no Brasil, por motivos socioculturais, sempre foi relegada a planos inferiores, e teve por retaguarda ideológica o elitismo acentuado do processo educacional, aqui instalado pelos jesuítas e a interpretação político-ideológica da oligarquia agrária conhecida popularmente na expressão: "gente da roça não carece de estudos. Isso é coisa de gente da cidade” (Anônimo) (LEITE, 1999 p. 14).

O direito à educação do campo foi materializado através da Constituição Federal de 1988 e da Lei de Diretrizes e Bases para a Educação (LDB), lei oㅡ. 9.394/1996, a qual propõe no artigo 28 :

Na oferta da educação básica para a população rural, os sistemas de ensino promoverão as adaptações necessárias a sua adequação às peculiaridades da vida rural e de cada região, especialmente: I - conteúdos curriculares e metodologias apropriadas às reais necessidades e interesses dos alunos da zona rural; II - organização escolar própria, incluindo adequação do calendário escolar às fases do ciclo agrícola e às condições climáticas; III - adequação à natureza do trabalho na zona rural (BRASIL/ MEC, LDB 9.394/96, art. 28). 
Na visão de Leite (1999), a LDB gerou a desvinculação da cultura escolar urbana da cultura escolar rural, demandando da escola rural um repensar e um planejamento relacionado à vida rural e, de certa forma, desurbanizado. Para consolidar essa intencionalidade de ruptura com o passado tradicional de uma escolarização/ educação que não abrangia as expectativas do povo do campo, corroboraram Fernandes, Cerioli, Caldart (2004) com um novo conceito de educação do campo:

A educação do campo é aquela que trabalha os interesses, a política, a cultura e a economia dos diversos grupos de trabalhadores e trabalhadoras do campo, nas suas diversas formas de trabalho e de organização, na sua dimensão de permanente processo, produzindo valores, conhecimentos e tecnologias na perspectiva do desenvolvimento social e econômico igualitário desta população (FERNANDES; CERIOLI; CALDART; 2004, p. 53).

A educação do campo precisa trabalhar a realidade, a vivência, as experiências e as expectativas sociais, culturais e econômicas do público a qual se destina. Essa educação precisa vir imbuída de uma marcante reflexão política e cidadã, do contrário, não obterá resultados concretos tão efetivos, já que a educação é uma ferramenta que visa preparar os sujeitos para o mundo do trabalho e para que estes adquiram um pensamento crítico reflexivo, em suas mais diversas dimensões.

Para Leite (1999):

A função primordial da escola é ensinar, transmitir valores e traços da história e da cultura de uma sociedade. A função da escola é permitir que o aluno tenha visões diferenciadas de mundo e de vida, de trabalho e de produção, de novas interpretações de realidade, sem, contudo, perder aquilo que lhe é próprio, aquilo que lhe é identificador (LEITE, 1999, p. 99).

Neste contexto, cabe-nos ressaltar que os componentes: território (chão onde vivemos), natureza (meio-ambiente), a soberania popular (cidadania), a resistência crítica e democrática e a renovação das lutas e dos ambientes institucionais, bem como as questões políticas, socioeconômicas, culturais, científicas e tecnológicas são subsídios transversos na educação do campo. Uma vez que à educação do campo deve-se resguardar uma concepção educativa que se materialize na escola, de modo que esta escola seja do campo e não apenas para o campo. Vivenciar uma proposta educativa do campo e no campo necessita da identificação e da edificação de uma identidade escolar banhada pela territorialidade e toda sua historicidade, cultura e formas de viver. 
Definidas pelas Diretrizes Operacionais para a Educação Básica do Campo (2002), a identidade da escola do campo pode ser assim mencionada:

Art. 2 - Parágrafo único. Aidentidade da escola do campo é definida pela sua vinculação às questões inerentes à sua realidade ancorando-se na temporalidade e saberes próprios dos estudantes, na memória coletiva que sinaliza futuros, na rede de ciência e tecnologia disponível na sociedade e nos movimentos sociais em defesa de projetos que associem as soluções exigidas por essas questões à qualidade social da vida coletiva do País (BRASIL, 2002, p. 37).

Júnior e Netto (2011) corroboram, ainda, que as instituições de ensino do campo devem estar preparadas para acolher à diversidade, às propriedades dos alunos que vivem nos espaços do campo, daí, a estima de se levar em cômputo as características e saberes do povo rural sem esquecer o que é corriqueiro a todos, admitindo o ingresso e o uso da ciência e das novas tecnologias.

Um longo processo de negligência e luta marcou a consolidação da educação do campo. No entanto, como foi visto anteriormente, esse direito começou a ser efetivado, carecendo ainda de mais debates, ações e políticas públicas que visem o fortalecimento das escolas do campo, principalmente quanto à construção de escolas adequadas à realidade do campo, com recursos financeiros e materiais tecnológicos que promovam uma educação de qualidade e igualitária. Enfim, há um longo caminho a percorrer, e esse caminho envolve todos os atores sociais ligados a este processo educativo, sobretudo no contexto do ensino de ciências.

\section{ensino de ciências na Educação do Campo}

As ciências estão presentes no currículo escolar desde os anos iniciais, pois são ferramentas importantes na busca pelo conhecimento e no seu questionamento. Falar da história, da geografia, do meio-ambiente, da vida animal e outros seres vivos, são temas muito corriqueiros no dia a dia de uma escola do ensino fundamental. Esse campo do conhecimento é importantíssimo nesta fase, visto que é na infância e na adolescência que os sujeitos são muitos curiosos, observadores e investigadores. Existe, neles, uma vontade imensa de explorar e conhecer o mundo que os cerca, então, nada melhor do que ter uma escola e um professor que desempenhem o papel de instigadores e promotores das atividades, ações e conhecimentos que saciem estas necessidades de forma crítica, reflexiva e consciente. 
Segundo Enisweler, Kliemann e Strieder (2015), o Ensino de Ciências na Educação do Campo é uma temática recente e, por conta disso, pouco se sabe sobre 0 que se tem produzido sobre o assunto nas últimas décadas. Alguns autores como Arroyo (2004), Molina (2004) e Caldart (2004) têm discutido as questões sobre a educação no campo, no entanto, temos pouco material específico que discorra sobre as ciências na educação do campo.

De acordo com Polato (2009), as escolas que obtiveram sucesso na sua ação pedagógica, voltada para as ciências, no contexto de escola do campo, privilegiaram os seguintes passos:

- Ajuntamento do ambiente e conhecimentos escolares com a realidade das crianças;

- Visibilização e inserção dos saberes do campo nos Projetos Políticos Pedagógicos e atividades escolares;

- Utilização de novos espaços para práticas de ensino, como por exemplo: rebanho de caprinos e ovinos, galinheiros, plantações familiares, áreas de caatinga, rios e outros;

- Relacionar os conhecimentos teóricos e práticos da vida e da educação no campo, com os abrolhados fora da conjuntura rural;

- Uma escola apta a trabalhar em parceria com a comunidade;

- Relação com outras instituições escolares do meio rural para o intercâmbio de experiências e saberes (POLATO, 2009).

O estudo das Ciências na realidade escolar do campo deve favorecer o aprendizado sobre os sujeitos que vivem nele, suas formas de sobrevivência e a evolução histórica de sua realidade social, econômica e cultural ao longo do tempo; dando atenção também a macro realidade, ou seja, aos aspectos do mundo material, como um todo, abrangendo o meio ambiente, com seus recursos naturais, e consequentes transformações ocasionadas pela ação do homem sobre a natureza; o conhecimento e a valorização da fauna, da flora e da vida, em suas mais variadas espécies e formas; a busca pelo conhecimento quanto ao Universo, o Sistema Solar e seus movimentos.

Conforme a Base Nacional Comum Curricular (BNCC) (2016, p. 136):

O ensino de Ciências, como parte de um processo contínuo de contextualização histórica, social e cultural, dá sentido aos conhecimentos para que os/as estudantes compreendam, expliquem e intervenham no mundo em que vivem, estabelecendo relações entre os conhecimentos científicos e a sociedade, reconhecendo fatores que podem influenciar as transformações de uma dada realidade (BRASIL, 2016, p. 136). 
É preciso repensar o papel do ensino das ciências da natureza desde o início da formação dos sujeitos, na perspectiva de fazer com que estes descubram o lugar do humano no ecossistema planetário, se percebam como elos da cadeia e da vida na natureza e/ou membro da comunidade de vida deste ecossistema chamado Planeta Terra. Que busquem nas ciências naturais uma forma de vida equilibrada e ambientalmente sustentável, tratando todos os recursos naturais e seres, em geral, de forma solidária, irmanada e respeitosa.

É notório que o desenvolvimento científico e tecnológico trouxe notáveis progressos para a humanidade e para todos os seus processos de produção, criação, serviços e explorações. No entanto, o desequilíbrio ambiental e social também já é visível e preocupa os estudiosos, como apregoa a BNCC:
A ação humana tem produzido grandes impactos e desequilíbrios na natureza e na sociedade. A condição e a competência de debater e tomar posições quanto os alimen- tos, medicamentos, combustíveis, transportes, saneamento e manutenção da vida na Terra demanda tanto conhecimentos éticos e políticos quanto científicos. Isso por si só justifica, na formação escolar, a presença das Ciências da Natureza, que têm em comum a observação sistemática do mundo material, com seus objetos, substancias, espécies, sistemas naturais e artificiais, fenômenos e processos, estabelecendo rela- ções causais, compreendendo interações, fazendo e formulando hipóteses, propondo modelos e teorias e tendo o questionamento como base da investigação (BRASIL, 2016, p. 136).

Considerando que antes de iniciar a vida escolar a criança já convive com aparatos tecnológicos e com fenômenos e transformações no seu cotidiano, o Ensino das Ciências da Natureza deverá partir das percepções prévias dos estudantes sobre o mundo natural e social no qual estão inseridos; do fenômeno que as educandas e os educandos podem observar no dia a dia da realidade imediata da comunidade e vão ampliando em diálogo com as realidades mais globais. A partir dessa primeira leitura de mundo serão expostos às educandas e aos educandos os conhecimentos científicos, devendo se ter o cuidado de proporcionar o diálogo do conhecimento científico acadêmico com o conhecimento popular; proporcionar momentos de aprendizagem nos quais os alunos aprendam novos conhecimentos e possam vivenciá-los, experimentá-los na realidade de sua comunidade e no seu cotidiano. E para que essa realidade se consolide, carecemos de professores das áreas de ciências com uma sólida formação que favoreça a vivência dessa nova realidade educacional. 


\section{Estágio e a formação de professores de ciências da Educação do Campo}

No Brasil, os cursos superiores de Licenciaturas em Educação se baseiam na Pedagogia da Alternância, com a finalidade de que a lida do plantio, colheita e capina não se tornem um obstáculo para os alunos frequentarem as escolas, além disso, promovem saberes que envolvem o cotidiano e a realidade do campo com saberem científicos e escolares.

O currículo dos cursos de Ciências da Educação do Campo tem um forte compromisso com o cruzamento/relação entre os conhecimentos científicos estudados e o cotidiano dos discentes e docentes.

O projeto curricular de ciências deve, pois, ser capaz de estabelecer pontes entre fenômenos e processos naturais ou tecnológicos, de um lado, e conceitos, modelos e teorias científicas, de outro. Por exemplo, para entender a formação dos solos e sua recuperação em áreas degradadas é importante compreender os modelos de decomposição de matéria orgânica e de ação de micro-organismos. Outros tópicos do currículo envolvem questões de ordem filosófica - qual é nosso lugar no universo?; do que é formada a matéria?; o que é vida? - que parecem estar mais distantes das vivências dos estudantes. A presença delas no currículo justifica-se pela necessidade de promover uma compreensão do que é a Ciência e como o conhecimento científico interfere em nossas relações com o mundo natural, com o mundo construído e com as outras pessoas (MARTINS, 2006, p. 65).

A formação de educadores na área das Ciências de Educação do Campo deve garantir que estes educadores e educadoras contribuam significativamente na superação do currículo e da disciplinarização urbanizada e hegemônica, dando espaço a criação e a expansão de conhecimentos e saberes contextualizados, territorializados, de acordo com a realidade daqueles que vivenciam o cotidiano acadêmico. A nova proposta curricular no contexto da educação do campo busca vivenciar em seu dia a dia acadêmico a valorização e a produção de conhecimentos e saberes advindos do meio rural e suas diversas expressões culturais, sociais, ambientais e econômicas. Dessa forma, ocorre uma articulação das temáticas trabalhadas, abarcando os conhecimentos específicos das Ciências Naturais (física, química, biologia), da Matemática e das Ciências Agrárias, de modo que todos esses temas sejam estreitamente contextualizados e vivenciados de acordo com a micro e macro realidade dos acadêmicos e de seus futuros alunos. Para garantir isso, os conhecimentos produzidos no meio acadêmico, no estágio e, posteriormente, em sala de aula, deverão ser trabalhados por meio de situações-problema reais. 
Para efetivar uma educação integral, de verdade, que abranja a amplitude da vida humana e todos os seus processos culturais, sociais, econômicos e históricos, objetivando a formação de cidadãos críticos, instigadores e politizados, Caldart (2015, p. 23) supõe um processo de formação inicial, continuado e contínuo, que requer um trabalho específico para isso, começando pelo investimento na formação dos/as educadores/as.

Na visão de Lima (2015, p. 61), é necessária:

Uma política de formação de educadores/as construída a partir da práxis educativa, que se constitui através da problematização crítica, tanto dos saberes e experiências socioculturais dos/as educadores/as quanto do contexto socioeducativo no qual estão inseridos, torna-se um caminho fecundo à formação de educadores/as enquanto intelectuais críticos que tenham capacidade de compreender a realidade social complexa e contraditória em que estão envolvidos os processos educativos e as vivências cotidianas do/as educandos/as (LIMA, 2015, p. 61).

Sobre os aspectos de relevância na formação dos educadores, que devem ser assumidos na proposta de educação do campo, Reis (2009) aponta que é de suma importância um processo de formação de educadores(as) que assuma os mesmos princípios pedagógicos da Educação Básica e do campo, de forma a permitir o desencadeamento de um processo educativo, a partir da reflexão sobre as condições e história de vida de tais educadores e formação, assim como os valores e as concepções de educação, de humanidade e de sociedade.

Assim, o processo de formação do professor do campo, seja na área das ciências naturais, na matemática, nas linguagens, nas ciências agrárias e outras, deve estar atenta a este processo formativo, que começa no ambiente acadêmico, perpassando pelo momento de estágio e subsecutivamente irá se suceder até a sua atuação profissional.

Sob esta égide, o estágio curricular é compreendido como um método de conhecimento objetivo e prático e que proporciona subsídios para compreender vastos ensinamentos que conduzem ao exercício da sua profissão crucial para a construção dos conhecimentos que se respalda em aproximar o estagiário à sociedade, cuja “dissociação entre teoria e prática resulta em um empobrecimento das práticas nas escolas, o que evidencia a necessidade de explicitar por que o estágio é teoria e prática (e não teoria ou prática)" (PIMENTA; LIMA, 2004, p. 41).

Ressaltamos que estágio é um meio de conectar o professor, aluno e escola, utilizando a educação como um trabalho colaborativo que gera inúmeras informações indispensáveis para a formação do educador, pois o educando, a partir desta vivência, se torna reflexivo, crítico, analista e mediador, como também, aproxima 
a teoria da prática de diversas formas cabíveis, para uma prática permeada pela incessante pesquisa, auto avaliação/reflexão, articulando, refletindo e compilando conhecimentos sobre as questões atuais das disposições do trabalho pedagógico, além disso, é uma forma de desenvolver fundamentos teóricos de acordo com o modelo da Educação do Campo e da Questão Agrária.

Na visão de Sposito (2013, p. 01):

Nos cursos de Licenciatura em Ciências da Natureza, o Estágio Supervisionado é o momento em que o licenciando forma um elo entre a escola da Educação Básica e a Universidade para aprofundar seus conhecimentos da profissão de professor e conhecer seu futuro local de trabalho. Na Escola de Educação Básica ele estará vinculado ao professor de uma determinada disciplina aprendendo com essa pessoa e também com os diversos profissionais da educação (diretores, supervisores pedagógicos, pessoal administrativo e da manutenção geral) além dos alunos, pais e de pessoas da comunidade, com o intuito de inteirar-se desse contexto escolar e de suas demandas (SPOSITO, 2013, p. 01).

Como salienta Sposito (2013), a ascensão da instrução de Ciências deve estar associada com a ideia de cidadania e da democracia, propiciando a interdisciplinaridade associada à multidisciplinaridade, por meio de práticas e didáticas que abarquem, como exemplo: o questionamento, a observação intencional, experimentos, aulas de campo, leitura de textos diversos, utilização de tecnologias, como a informática, e a sistematização dos conhecimentos por meio das diversas mídias, em sintonia com o sugerido pelos Parâmetros Curriculares Nacionais de Ciências Naturais (PCN). Esses momentos são de suma importância, tanto nos momentos de estágio quanto na atuação profissional propriamente dita.

Já para Krasilchik (1996) o estágio é o momento que oportuniza ao aluno de Ciências da Natureza a apreensão concreta das técnicas, conceitos e estratégias de trabalho, é onde ele visualiza de forma mais ampla os impactos físicos, químicos e biológicos dos conhecimentos e tecnologias desenvolvidos teoricamente. Tais conhecimentos, futuramente, em sua atuação docente, devem, portanto, contribuir para formar cidadãos que sejam capazes de utilizarem o que aprenderam na escola para tomar decisões que promovam como via de regra a promoção de benefícios éticos e coletivos da sociedade em que estão inseridos.

O estágio é considerado um dos momentos mais significativos para a formação docente. É nesse momento que deparamos com a realidade na qual os licenciandos serão inseridos após a conclusão do curso. O estágio traz consigo três etapas: observação, coparticipação e docência. Nestes momentos, torna-se possível consolidar 
a importância do conhecimento cientifico, expandindo nossa capacidade de compreender o mundo, de refletir criticamente sobre ele e nele atuar, como também, a oportunidade da convivência com profissionais mais experientes (PIMENTA; LIMA, 2011). O estágio enriquece o progresso de uma formação alicerçada no contexto real na qual possibilita a construção independente do conhecimento cientifico por meio da vivência. Desta forma, "o estágio é o eixo central na formação de professores, pois é através dele que o profissional conhece os aspectos indispensáveis para a formação da construção da identidade e dos saberes do dia a dia" (PIMENTA; LIMA, 2004, p. 56). É indispensável no desenvolvimento da formação do professor licenciado em Educação do Campo com Habilitação em Ciências da Natureza, porque oferece enorme chance de desenvolvimento, estimula a comunicação e o relacionamento interpessoal, como também a aquisição de experiência.

Assim sendo, o educando pode aprender melhor o conhecimento sobre a carreira escolhida, por meio da experiência transposta durante o tempo de estágio. Além disso, a formação de professores de Ciências da Natureza da Educação do Campo se funda na prática do ensino, que busca trazer elementos de análise e reflexão para a formação inicial do licenciando, de tal forma que construa visões sobre o ensino de Ciências e aprendizagens baseadas nas experiências pessoais desenvolvidas durante o estágio curricular obrigatório, se constituindo nas percepções e habilidades previamente construídas durante o curso, que, a propósito, caracteriza-se em uma luta dos povos do campo por políticas públicas que garantam o seu direito à educação, que seja no e do campo ${ }^{1}$. Formando, deste modo, professores de Ciências que favoreçam o estabelecimento de interações dialógicas professor-aluno, em sala de aula, e preparação do conhecimento científico, a partir dos instrumentos que contribuam para interferir na realidade.

\section{Delineamento metodológico}

Para a construção deste artigo foram realizadas pesquisas bibliográficas, com abordagem qualitativa, e pesquisas documentais nos relatórios e projetos desenvolvidos durante o Estágio Supervisionado I do curso de Licenciatura em Educação do Campo com Habilitação em Ciências da Natureza da Universidade Federal do Recôncavo da Bahia (UFRB).

O estágio foi desenvolvido numa comunidade situada na zona rural. Esta comunidade tem peculiaridades e realidade próprias, pensando nisso, realizamos 
uma pesquisa de campo/local com o intuito de conhecer o público alvo do estágio. De acordo com Gil (2008) a pesquisa de campo busca realizar o aprofundamento acerca de uma realidade específica. É basicamente realizada por meio da observação direta das atividades do grupo estudado e de entrevistas com informantes para captar as explicações e interpretações do que ocorre naquela realidade. A pesquisa procurou focar na coleta das seguintes informações: nome da escola onde o estágio foi realizado, endereço, número de funcionários e professores, número de alunos, área extensiva e quantidade de cômodos da escola, contatos dos professores e direção, quantidade de turmas e respectivas séries; objetivos e missão da instituição escolar. Além da pesquisa local, foram realizadas, conjuntamente, pesquisas documentais e bibliográficas, com abordagem qualitativa, as quais contribuíram para fortalecer os conhecimentos do estagiário quanto à realidade da escola do campo e as principais tendências teóricas que marcam a temática no momento da pesquisa. Os autores mais estudados na pesquisa bibliográfica foram: Caldart (2004), Molina (2004), Arroyo (2004), Fernandes (2004), Leite (1999), Pimenta e Lima (2011), dentre outros.

Como instrumento de coleta de dados o estagiário utilizou observações, diálogos informais, fotografias e entrevistas com o público alvo do estágio.

O estágio foi baseado no Projeto de Aprendizagem do acadêmico, na realidade da educação do campo local e no planejamento e no Projeto Político Pedagógico, construído pela escola. Sendo constituído por três momentos metodológicos importantes, assim definidos: Observação, coparticipação e docência. Estas três fases foram muito importantes para a plena interação, aprendizagem e desenvoltura do estagiário com sua turma e a professora supervisora.

Como forma de garantir e resguardar os aspectos éticos, o estágio foi formalizado a partir de convênio estabelecido entre universidade e instituição concedente. Foram omitidos dados que pudessem identificar os sujeitos envolvidos na pesquisa, emitindo apenas aqueles que tratem da instituição concedente e do estagiário.

\section{Vivências de estágio supervisionado em ciências da natureza em uma} escola do campo

O Estágio Supervisionado I foi realizado na Escola Municipal do Assentamento Alto Bonito - EMAB, situada na Zona Rural do município de Cansanção-Bahia. O contexto educacional era de uma Escola do Campo. A professora supervisora 
do estágio era uma pedagoga com larga experiência na docência no campo, a qual contribuiu de forma gigantesca no processo de formação do estagiário. Durante todo este processo de formação, o graduando teve a oportunidade de pôr em prática parte das teorias estudadas ao longo do curso de graduação, essa prática se deu tanto nos momentos de observação quanto nos do planejamento e execução das aulas. Ao longo de sessenta e oito (68) horas de efetivo trabalho docente foram realizadas atividades junto aos alunos e o corpo docente da escola como um todo.

As atividades desenvolvidas em sala de aula se basearam no planejamento da professora supervisora e no Projeto Político Pedagógico (PPP) da escola, enriquecidas com as temáticas que envolvem a escola do campo, as quais foram trazidas pelo estagiário. Os momentos mais importantes do estágio foram:

a) Investigação e pesquisas documentais: neste momento foram realizadas pesquisas documentais que interessavam ao estagiário e contribuiriam no seu processo de aprendizagem. O estagiário buscou conhecer o Estatuto da Escola, o PPP da escola, a composição da Diretoria e do Corpo do Docente, o número de alunos que estudavam na escola, o número de funcionários e a realidade da escola, de uma forma genérica e simplificada; em seguida coletou as assinaturas, termos e declarações exigidas pela UFRB, como requisitos documentais do Estágio Supervisionado I, para o estabelecimento da parceria entre escola e universidade.

Segundo Gil (2002, p. 62), a pesquisa documental proporciona diversas prerrogativas por ser "fonte rica e estável de dados: não implica altos custos, não exige contato com os sujeitos da pesquisa e possibilita uma leitura enraizada das fontes". Gil (2002, p. 62) complementa que "ela é parecida com a pesquisa bibliográfica, o que as diferencia é a natureza das fontes, sendo a documental aquela que ainda pode ser reelaborada de acordo com os objetivos da pesquisa".

b) A observação: se constitui na primeira etapa do estágio, que teve como objetivo possibilitar a coleta de dados e informações que serviram de auxílio para as etapas seguintes do mesmo.

O educador que pretende obter êxito nos resultados almejados durante sua docência, precisa se manter na posição de observador, pois a partir da observação poderá realizar possíveis ajustes durante o processo de ensino aprendizagem, quebrando a dicotomia Teoria/prática (ARAÚJO; PORTO, 2019). Na visão de Aragão 
e Silva (2012, p. 50) a "observação se constitui de uma ação fundamental para análise e compreensão das relações que os sujeitos sociais estabelecem entre si e com o meio em que vivem".

Neste momento, o estagiário observou as aulas ministradas pela professora supervisora. As atividades consistiam em conteúdos voltados para o acontecimento das Olímpiadas realizadas no Brasil. Essa temática foi trabalhada de forma abrangente, de modo que foram realizados jogos, brincadeiras, questionários, avaliações e rodas de conversas para dialogar os pontos positivos e negativos trazidos pela olímpiada no país. Neste período o estagiário apenas observava e contribuía de forma a não intervir na realidade da classe.

Ao observar a realidade de ensino de Ciências, obtivemos várias impressões acerca desta fase, principalmente quanto à importância da contextualização e da interdisciplinaridade dos conteúdos estudados em sala de aula. Nesta etapa pudemos participar de algumas ações, como diagnóstico de aprendizagem dos alunos, no qual usamos os conhecimentos adquiridos com instrumentos para determinar os fatores influentes em uma determinada situação. Nesse espaço foi possível conhecer os estudantes e suas práticas, realizar observações na reunião de pais e mestres, que, segundo a Lei de Diretrizes e Bases (BRASIL, 1996), a educação abrange os processos formativos que se desenvolvem na vida familiar, portanto se faz necessário a presença da família no ambiente escolar.

Essa experiência nos possibilitou desenvolver novos aprendizados, além dos adquiridos na universidade, bem como elaborar maneiras de partilhar a teoria e a prática, nesta busca constante da formação do educador. Pois, segundo Freire (2004), a observação é uma ação altamente reflexiva quando o olhar está pautado para buscar ver o que ainda não sabe. Não é um olhar vago, a espera de descobertas. É um olhar focalizado para detectar, diagnosticar o saber e o não saber do grupo. Freire descreve deste modo a observação como um exercício crucial para as funções de um educador, dividido em cinco exercícios que, de fato, favorecem a construção do conhecimento. Esses elementos são: a capacidade de silenciar, escutar, olhar, escrever e participar, focando no compromisso com a atividade docente com a turma, o professor, a escola e os funcionários. Araújo e Porto (2019) complementam que, é a partir deste momento que há a aproximação da realidade com a escola, a fim de compreender os desafios a serem enfrentados nas próximas etapas, pois a 
execução da prática só se faz possível conhecendo os problemas e planejando, para, desta forma, poder contribuir com o desenvolvimento do educando.

c) Coparticipação: a partir deste momento o estagiário começou a contribuir de forma mais aprofundada com as temáticas e aulas realizadas em sala de aula. Foi nessa fase que o estagiário começou a interagir com a turma e a auxiliar a professora supervisora em pequenas ações, tais como: nas suas atividades de rotina, como, por exemplo, a elaboração de exercícios e, até mesmo, de materiais avaliativos, ajudando, quando solicitada, na formação de grupos, na supervisão dos mesmos, orientação, chamada no diário de classe, orientações em pesquisas, colaborando com os planejamentos de aulas durante os Acompanhamentos Complementares, correções de provas/atividades, entre outros pontos.

Araújo e Porto (2019, p. 12) complementam que:

[...] no cotidiano acadêmico é perceptível que os graduandos se envolvam com muita disposição e ânimo quando a universidade lhes proporciona a participação em que consigam colocar conhecimentos teóricos em prática, acompanhados de um profissional supervisor ou quando possui uma instituição conveniada que estão em permanente contato com a universidade.

Sendo assim, o papel do estagiário, nesta fase do estágio, foi a de mediar os conhecimentos através da metodologia do 'aprender fazendo', pois para Vieira (1997, p. 76) apud Araújo e Porto (2019, p. 12) “a Licenciatura é voltada para a preparação do profissional de ensino fundamental e médio, onde o mesmo elabora e executa os programas adequados aos seus alunos”. É uma fase preparatória para a docência da sala.

d) Regência/docência: neste momento o estagiário começou a ministrar aulas efetivamente. Foi possível realizar suas atividades próprias, embasadas nas ações contidas no projeto pedagógico, com base nas necessidades da turma, a fim de contribuir, embora por um curto período de tempo, com o desenvolvimento e aprendizado dos educandos.

Neste período de regência os assuntos mais trabalhados foram: os Jogos olímpicos; Manifestações culturais; As substâncias e as misturas; As reações químicas; as Forças; A atração gravitacional. Esses conteúdos trabalhados com a turma do nono ( $\left.9^{\circ}\right)$ ano eram interligados aos conhecimentos já obtidos pelos alunos dentro da sua própria realidade e na sua convivência familiar e comunitária. 
Na visão de Pimenta e Lima (2011, p. 61),

[...] o estágio atua como campo de conhecimento e eixo curricular central nos cursos de formação de professores e possibilita que sejam trabalhados aspectos indispensáveis à construção da identidade, dos saberes e das posturas especificas ao exercício profissional docente.

Já para França (2009, p. 168)

[...] o estágio no nível de regência carrega consigo a responsabilidade de oferecer condições para que os futuros professores possam interagir com a situação de ensino e, principalmente, possam apropriar-se de um saber-fazer advindo da experiência coletiva dos professores.

Devido ao fato de o Brasil estar sediando os jogos olímpicos foram trabalhados conteúdos que instigavam a reflexão crítica dos alunos quanto aos benefícios e malefícios trazidos pela olímpiada para a população brasileira.

O estagiário lecionou aulas por toda a III Unidade, no lugar da professora regente; aplicou provas e revisões durante o mesmo período, realizou atividades de campo, experiências físicas, químicas e biológicas, que eram interligadas aos conteúdos por ele planejados e a realidade territorial e comunitária dos discentes.

A experiência vivenciada levou o acadêmico a conhecer e atuar no cotidiano de um professor. Observou, participou, planejou, executou e avaliou os alunos e suas atividades, nos diversos momentos do estágio (observação, coparticipação e docência). Durante seu período de estágio na educação do campo, o acadêmico teve diversas experiências concretas que envolviam alunos, professores e comunidade local. Essa experiência favoreceu a prática das teorias vistas no meio acadêmico, oportunizando mais aprendizado e experiência profissional. Pois "compreender a escola em seu cotidiano é condição para qualquer projeto de intervenção, pois o ato de ensinar requer um trabalho especifico e reflexão mais ampla sobre a ação pedagógica que ali se desenvolve" (PIMENTA; LIMA, 2009, p. 104).

Desse modo, ressaltamos que o Estágio Supervisionado I, foi um momento que serviu para o estagiário pensar/refletir no seu fazer docente. Possibilitou uma aproximação com a prática do ensinar. Estagiar na realidade do povo do campo com a educação do campo permitiu ao acadêmico aprimorar seu olhar; instigou o desejo de fazer algo diferente, de fazer a diferença no âmbito escolar, de ampliar os fazeres enquanto professores, partindo de novos saberes reflexivos e libertadores. Pois, como disse Freire (1987, p. 32): 
A pedagogia tem de ser forjada com ele (o oprimido) e não para ele, enquanto homens ou povos, na luta incessante de recuperação de sua humanidade. Pedagogia que faça da opressão e de suas causas objeto da reflexão dos oprimidos, de que resultará o seu engajamento necessário na luta por sua libertação, em que esta pedagogia se fará e refará (FREIRE, 1987, p. 32).

Estagiar no campo fez aflorar o entendimento sobre o que realmente é uma educação integral, a qual está intimamente ligada as dimensões física, psíquica, emocional, intelectual, cultural, social e econômica de cada sujeito, comunidade e sua história. O estagiário entendeu que é preciso fazer das atividades não somente um conteúdo a ser aprendido, mas sim uma nova experiência escolar que contribua para a melhor convivência e sobrevivência do sujeito na sua realidade local e abrangente. Ou seja, é preciso ensinar vivenciando as realidades micro e macro dos sujeitos envolvidos no processo de ensino-aprendizagem. Pode-se dizer que o professor vai instigar o aluno a ler o livro e a partir dele também ler seu mundo, ler com os olhos, com o coração, com a consciência crítica, com a vontade de transformar a realidade posta e opressiva.

Segundo Freire (1982, p. 109-110),

Não há conscientização se, de sua prática não resulta a ação consciente dos oprimidos, como classe social explorada, na luta por sua libertação. Por outro lado, ninguém conscientiza ninguém. O educador e o povo se conscientizam através do movimento dialético entre a reflexão crítica sobre a ação anterior e a subsequente ação no processo daquela luta (FREIRE, 1982, p. 109-110).

As atividades desenvolvidas no estágio foram elaboradas com muita atenção, pois nem todos os alunos tinham a mesma desenvoltura e aprendizagem. As atividades foram realizadas com materiais adquiridos pelos próprios alunos, dessa forma, eles levaram materiais que conheciam e tinham à sua disposição, além de já conhecerem algumas utilidades deles. A escola tinha seu próprio Projeto Político Pedagógico, nele a educação do campo foi privilegiada e tinha forte conectividade com a realidade do seu território. Todas as atividades realizadas com os alunos foram baseadas na sua realidade local; buscou-se mostrar, através de experiências das pessoas mais velhas da comunidade, por meio de diálogos, os objetos concretos da vida e do trabalho no campo, coisas do seu cotidiano real; tudo que era mostrado ou discutido era questionado e refletido, com o intuito de promover uma relação ética entre o que é certo e é errado, buscando destacar os valores humanos, da pluralidade e da 
inclusão. Através dessas atividades os alunos, professores e estagiário perceberam que a escola não estava distante da realidade local.

Destacamos para os licenciandos que estão iniciando a docência os impactos das ações/atividades que o estágio traz para a realidade, como um instrumento de orientação para a graduação em licenciatura, com conteúdos específicos que culminam na retomada de conteúdos estudados, para a vivência dos conceitos que dialogam com a interdisciplinaridade em práticas educativas, entre teorias e aplicações de produções autônomas em sala de aula (ARAÚJO; PORTO, 2019).

O estágio executado com abertura para o diálogo e troca de experiências. É interessante ressaltar que tal disposição não ocorre por acaso. Há todo um processo de preparação docente que ocorre na universidade durante a formação inicial, cujo entorno é carregado de significados delineados no curso de licenciatura, porque somos formados como sujeitos sociais e culturais situados, conectados a práticas concretas de um lugar, espaço e tempo (MILANESI, 2012, p. 218).

Portanto cada etapa trabalhada no estágio não deve ser refletida como um experimento qualquer, e sim vista como uma experiência de suma importância para a vida do licenciando, pois é através dela que ele estabelece uma conexão com as atividades da sua formação. Desta forma, o estagiário alcançou os objetivos almejados em seu estágio, pois vivenciou na prática as teorias vivencias em sala de aula e teve a oportunidade de reafirmar sua opção pela docência. Pois, como afirma Pimenta e Lima (2004, p. 56) a "relação dos saberes teóricos e saberes práticos durante todo o percurso da formação, garante, inclusive, que os alunos aprimorem sua escolha de ser professor a partir do contato com as realidades de sua profissão".

Pode se afirmar que todos os resultados esperados pelo estagiário, professora supervisora e professor orientador foram alcançados, visto que o acadêmico obteve um estágio que privilegiou os quatro momentos importantes do processo: investigação e pesquisa documental, observação, coparticipação e regência. Além disso, as atividades planejadas pela supervisora e o estagiário foram realizadas em sintonia com a realidade e a contextualização territorial, cultural, social e econômica dos alunos.

Um único fator negativo foi detectado no processo de estágio, o qual o aluno também relatou no seu relatório final, que é referente à pequena carga horária exigida pela universidade. $\mathrm{O}$ acadêmico gostaria de ter tido mais tempo para desenvolver outras atividades junto à escola. 


\section{Considerações finais}

Finalizando este trabalho pode se afirmar que os objetivos estabelecidos foram alcançados de forma satisfatória, visto que o mesmo contribui para instigar a discussão acerca da educação do campo a partir da experiência do licenciando no seu campo de estágio.

Como foi apontado no tópico dos resultados, o acadêmico obteve diversos ganhos no campo da experiência profissional e intelectual, além de ter contribuído para a produção de novos conhecimentos e experiências pedagógicas voltadas para os alunos de uma escola do campo.

A partir da experiência vivida no campo de estágio, no qual o acadêmico pode concretizar suas teorias e experiências acadêmicas, concluiu-se que as escolas do campo ainda precisam ser mais bem estruturadas física, material e financeiramente, além de se fazer necessário uma formação continuada dos professores, com foco na educação do campo e a contextualização territorial do currículo escolar. Foi visto que a escola avançou muito quanto às práticas pedagógicas, o próprio Projeto Político Pedagógico da escola privilegia a educação do campo, no entanto, as precárias condições da escola, dos equipamentos e a falta de tecnologias, para estudos mais avançados (laboratórios para experiências diversas, computadores, canteiros, farmácia viva, e outros), impedem que os profissionais e alunos avancem na qualidade do ensino e da aprendizagem.

Sugere-se que os movimentos sociais de camponeses e de estudantes continuem lutando pelo direito a uma educação do campo com mais qualidade e investimentos. Que os debates acerca das escolas do campo sejam cada vez mais divulgados e realizados, que os estudos acadêmicos e publicações sejam expostos de forma ampla e rotineira, tudo isso com o forte intuito de trazer melhores condições para as escolas e seu público alvo. Deste modo, o licenciando compromete a continuar estudando a temática no seu Estágio Supervisionado II e a atuar novamente numa escola do campo, tudo isso com o forte intuito de promover diálogos, atividades e experiências que disseminem a importância da valorização e da consolidação das escolas do campo. 


\section{Stage experiences of nature sciences in the context of field education: a critical-reflective analysis}

\section{Abstract}

The objective of this article was to report on the experiences of supervised internship development as a way of discussing the importance of the internship in the initial training of field science teachers. To do this, we sought to relate bibliographical references of important authors to the discussion of rural education, such as Arroyo (2004), Caldart (2004/2009), Molina (2004), Fernandes (2004) and others, with the experiences and the author's experiences in his or her field of study. The Supervised Internship I in the area of Natural Sciences was held in the Alto Bonito settlement, in Cansanção - Bahia, at the Alto Bonito Settlement Municipal School, with the ninth grade class of the educational institution. Bibliographical, documentary and local researches with a qualitative approach were based on the writing of this article, which was also influenced by the data collected through observation, dialogues, interviews and activities during the internship. Among the most important results, we can highlight the range of new knowledge and experiences obtained by the trainee and the students of the rural school, in addition to the precariousness and lack of technological and financial investments in the rural school institutions, which makes it difficult to the realization of an integral and quality education.

Keywords: Field Education. Science teaching. Supervised internship. Teacher training.

\section{Nota}

1 Segundo Caldart (2004, p. 149-150): "no: o povo tem direito a ser educado onde vive; do: o povo tem direito a uma educação pensada desde o seu lugar e com a sua participação, vinculada a sua cultura e às suas necessidades humanas e sociais".

\section{Referências}

ARAÚJO, A. S.; PORTO, K. S. Vivências de estágio supervisionado em Ciências da Natureza em uma escola do campo: reflexão das práticas pedagógicas na formação inicial de professores da Educação do Campo. Rev. Bras. Educ. Camp., Tocantinópolis, v. 4, e4132, 2019. DOI: http:// dx.doi.org/10.20873/uft.rbec.e4132.

ARAGÃo, R. F.; SILVA, N. M. da. A Observação como Prática Pedagógica no Ensino de Geografia. Fortaleza: Geosaberes, 2012.

ARROYO, M. G.; CALDART, R. S.; MOLINA, M. C. Por uma educação do campo. Petrópolis: Vozes, 2004.

BARAÚNA, R.S. Formação de professores e educação do campo: análise de uma proposta de formação superior e repercussões em um município baiano. 2009. Disponível em: http://books. scielo.org/id/bxgqr/pdf/cunha-9788523209025-09.pdf. Acesso em: 15 de julho de 2019. 
BRASIL - Ministério da Educação - Base Nacional Comum Curricular - BNCC. Proposta Preliminar, Segunda Versão, Revista-abril, 2016.

Constituição da República Federativa do Brasil - 1988. Disponível em: http://www. planalto.gov.br. Acesso em: 15 de julho de 2019.

Lei de Diretrizes e Bases da Educação Nacional - LDB (Lei no 9394/96). Rio de Janeiro: Qualithmark Editora, 1997.

Ministério da Educação - Diretrizes Operacionais para a Educação Básica nas Escolas do Campo. Brasília, DF, 2002.

CALDART, R. S. Educação Do Campo: Notas para uma Análise de Percurso. 2009. Disponível em: http://www.scielo.br/pdf/tes/v7n1/03.pdf. Acesso em: 14 de julho de 2019.

2015.

Caminhos para Transformação da Escola. São Paulo: Editora Expressão Popular,

CARVALHO, C. de S.; FELICIANO, F. J.; LUCAS, L. B. Abordagens metodológicas de ensino na formação inicial de professores de Ciências e Biologia: um curso formativo sobre o enfoque histórico-filosófico da Ciência. RBECM, Passo Fundo, v. 1, n. 2, p. 155-173, jul./dez. 2018.

ENISWELER, K. C.; KLIEMANN, C. R. M.; STRIEDER, D. M. O ensino de ciências na educação do campo: uma pesquisa em dissertações e teses. Disponível em: http://cac-php.unioeste. br/eventos/senieeseminario/anais/Eixo3/O_ENSINO_DE_CIENCIAS_NA_EDUCACAO_DO_CAMPO_UMA_PESQUISA_EM_DISSERTACOES_E_TESES.pdf.Acesso: 30 de julho de 2019 .

FERNANDES, B. M.; CERIOLI, P. R.; CALDART, R. S. Primeira Conferência Nacional Por uma educação básica do campo. 2004. Disponível em: file://C:/Users/Mira/Downloads/POR\%20 UMA $\% 20$ EDUCAO $\% 20 D O \% 20 \mathrm{CAMPO} \% 20 \% 20$ percursos $\% 20$ histricos $\% 20 \mathrm{e} \% 20$ possibilidades $\% 20$ _\%20Astrogildo\%20F.\%20da\%20Silva\%20Jnior\%20e\%20Mrio\%20Borg\%20(1).pdf. Acesso: 15 de julho de 2019.

FRANÇA, D. S. Formação do pedagogo: a orientação dos estágios de ensino pelo professor da escola básica. IX Congresso Nacional de Educação - EDICERE. III Encontro Sul Brasileiro de Psicopedagogia, 26 a 29 de outubro de 2009.

FREIRE, M. Observação, Registro, Reflexão: Instrumento Metodológico. Série Seminários. São Paulo: Espaço Pedagógico, 1992.

FREIRE, P. Pedagogia do Oprimido. Rio de Janeiro: Paz e Terra. 1987.

Terra, 1982.

Ação Cultural para a Liberdade e outros escritos. 6. ed. Rio de Janeiro: Paz e

GIL, A. C. Como elaborar projetos de pesquisa. 4. ed. São Paulo: Atlas, 2002.

JÚNIOR, A. F. S; NETTO, M. B. Por uma Educação do Campo: percursos históricos e possibilidades. Revista Eletrônica de Culturas e Educação. Caderno temático: Cultura e Educação do Campo N. 3 p. 45-60; Ano 2, 2011.

KRASILCHIK, M. Prática de Ensino de Biologia. 3. ed. São Paulo: Harbra, 1996.

LACKI, P. Educação rural: para quê? E para quem? 2005. Disponível em: http://www.polanlacki. com.br Acesso em: 15 de julho de 2017. 
LIMA, M. E. C. C.; PAULA, H. F.; SANTOS, M. L. B. Ciências da Vida e da Natureza no Curso de Licenciatura em Educação do Campo da UFMG. 2015. Disponível em: http://posgrad. fae.ufmg.br/posgrad/viienpec/pdfs/938.pdf. Acesso em: 30 de julho de 2019.

LEITE, S. C. Escola rural: urbanização e políticas educacionais. São Paulo: Cortez, 1999.

MARTINS, C. M. C. et. al. Ciências Ensino Fundamental: Proposta Curricular para Educação Básica. Secretaria Estadual de Educação de Minas Gerais. Diretoria de currículos, 2006.

MILANESI, I. Estágio supervisionado: concepções e práticas em ambientes escolares. Educar em Revista, Curitiba, n. 46, p. 209-227, out./dez. 2012. Editora UFPR

PIMENTA, S. G.; LIMA, M. S. L. Estágio e Docência. São Paulo: Cortez, 2004.

Estágio e docência. 6. ed. São Paulo: Cortez, 2011.

POLATO, A. Ensino com a cara do campo. Artigo publicado no Site Gestão Escolar, 2015. Disponível em: https://gestaoescolar.org.br/conteudo/777/ensino-com-a-cara-do-campo. Acesso em: 30 de julho de 2019 .

SILVA, S. A. P. S. Estágios Curriculares na Formação de Professores de Educação Física: o Ideal, o Real e o Possível. Revista Digital. Buenos Aires, v.10, n.82 p. 3-5, Março, 2005.

SPOSITO, N. E. C. O Estágio Supervisionado e o Ensino de Ciências. 2013. Disponível em: http://www.nutes.ufrj.br/abrapec/viiienpec/resumos/R1294-1.pdf. Acesso: 30 de julho de 2019.

REIS, E. dos S. A contextualização dos conhecimentos e saberes na perspectiva da contextualização dos conhecimentos e saberes da escola do campo. Salvador: UFBA: FACED: Programa de Pós-graduação em Educação, Sociedade e Práxis Pedagógica. (Tese de Doutoramento), 2009.

REIS, E.; CARVALHO, L.; NOBREGA, L. (org.). Educação e convivência: reflexões por dentro da UNEB. Juazeiro/Ba; UNEB/DCH III; NEPEC-SAB, 2011. 